\title{
Design and Simulation of Constant Voltage Variable Frequency Single Phase to Single Phase Cycloconverter in Simulink
}

\author{
B.O Akinloye ${ }^{1}$, Chinenye D. Okwudibe ${ }^{2}$ \\ Electrical and Electronics Engineering Department, Federal University of Petroleum Resources, Effurun, Delta State, \\ Nigeria $^{1}$ \\ Information and Communication Technology Center, Niger Delta University,Wilberforce Island, Bayelsa State, \\ Nigeria $^{2}$
}

\begin{abstract}
Cycloconverters convert alternating current of certain magnitude and frequency to another alternating current of another magnitude or frequency. Many of the industrial applications require variable frequency. The cycloconverter plays a pivotal role in achieving this task of supplying variable frequency. There are many types of cycloconverters depending on the number of phases that it is intended to convert the AC voltage to. Simulink is a graphical extension to MATLAB for modeling and simulation of systems. One of the advantages of Simulink is the ability to model a nonlinear system, in which a transfer function is not able to do. Another advantage of Simulink is that, it has the ability to take on initial conditions. In this work, a variable frequency constant voltage cycloconverter will be designed and simulated using Simulink.
\end{abstract}

Keywords: Cycloconverter, Matlab Simulink, Single-Pahse, Thyristor.

\section{INTRODUCTION}

The advent of high power ratings power electronics has brought about great improvement in the technology of power conversion. Before this time, to convert from $\mathrm{AC}$ to $\mathrm{AC}$, there must be conversion from $\mathrm{AC}$ to $\mathrm{DC}$ first and then the $\mathrm{DC}$ be inverted back to AC [1]. This always involves more components. Nowadays, AC can be converted directly to AC without passing through any intermediate step of DC. This has been a good improvement in the field of power electronics. Note that this is a two-stage process with an intermediate dc stage.

A cycloconverter is a type of power controller in which an alternating voltage at supply frequency is converted directly to an alternating voltage at load frequency without any intermediate D.C stage [2]. A cycloconverter is to be controlled through the timing of its firing pulses, so that it produces an alternating output voltage. By controlling the frequency and depth of phase modulation of the firing angles of the converters, it is possible to control the frequency and amplitude of the output voltage [3, 4]. Cycloconverters are simply the direct type converters used in high power applications. They are used in driving induction and synchronous motors. They are usually phase-controlled and they traditionally use thyristors due to their ease of phase commutation [5]. Thus, a cycloconverter has the facility for continuous and independent control over both its output frequency and voltage. This frequency can normally be converted up to a magnitude less than $1 / 3$ of the input frequency. The quality of the output voltage wave and its harmonic distortion also impose the restriction on this frequency. The distortion is very low at low output frequency [5].

Among the power converters used for driving electric motors, cycloconverter have the major advantages of its natural commutation and lack of energy storage. With these two advantages, its use in variable speed motor drives is up to 1400rev/min and in wide frequency range applications with high frequency link is most favorable [6]. In [7] a single phase cycloconverter circuit, which could generate variable frequency, was designed. The proper generation of the blanking and gate pulses of the switching devices and also synchronizing them with the input signal are the most important things in designing a cycloconverter circuit which becomes easier due to the availability of the integrated circuit. Here 555 timer and operational amplifier IC's have been used for generation of blanking and triggering signals. The synchronization of these signals with the input signal is performed by means of the comparator circuit where the operational amplifier IC is used. However beautiful and easier this approach may be, the inability of ICs to operate under high temperature will likely be a draw back. [8] designed a control circuit to provide a proper sequence of pulses for the semiconductor switches of the cycloconverter power circuit. The control circuit is designed using the Op amps and logic gates. The designed control circuit was simulated using the OrCAD Pspice software. 
The basic principle of operation of a cycloconverter is explained with reference to an equivalent circuit shown in figure 1. Each two-quadrant converter (phase-controlled) is represented as an alternating voltage source, which corresponds to the fundamental voltage component obtained at its output terminals. The diodes connected in series with each voltage source, show the unidirectional conduction of each converter, whose output voltage can be either positive or negative, being a two-quadrant one, but the direction of current is in the direction as shown in the circuit, as only thyristors unidirectional switching devices, are used in the two converters. Normally, the ripple content in the output voltage is neglected.

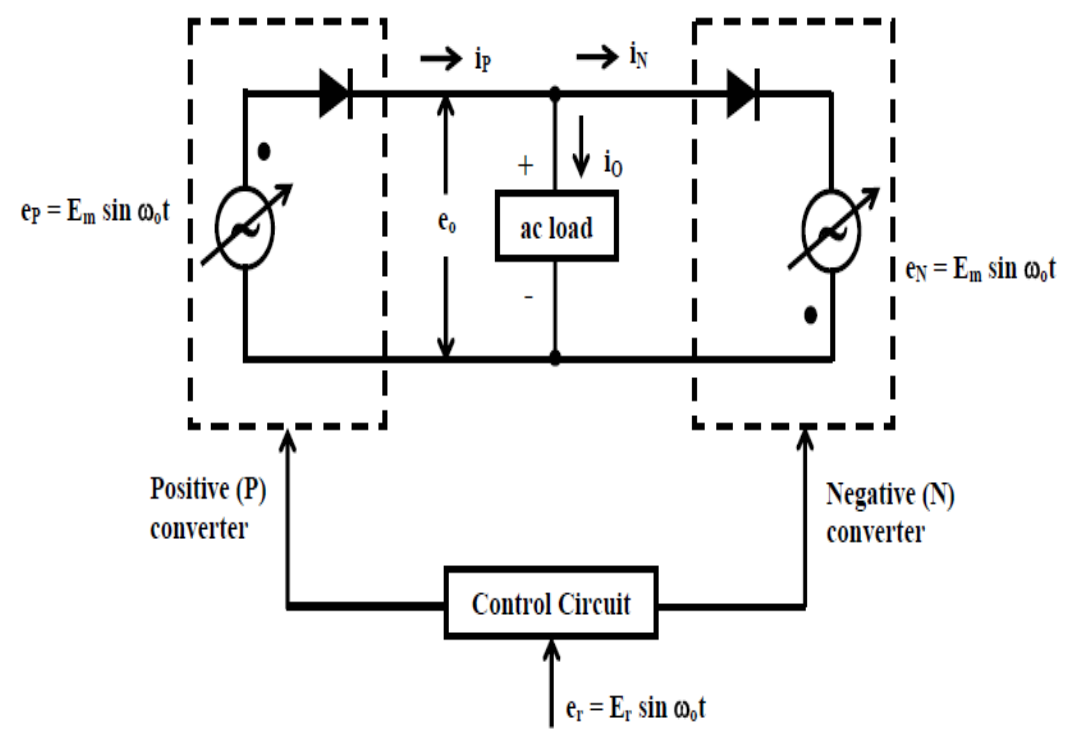

Fig. 1: Equivalent Circuit of Cycloconverter.

\section{METHODOLOGY}

Simulink is simulation software embedded in Matlab. It is a user friendly which is very easy to understand and to use. It is also a modern simulation software package. MATLAB SIMULINK is specially designed for simulating dynamic systems. It solves numerical problems in a fraction of time compared to other software packages, and it is more interactive than others. In this work the MATLAB-SIMULINK packages have been used for modeling and simulating the cycloconverter circuit and the waveform of the simulated circuit are presented.

Cycloconverters are the naturally commutated frequency converters that are synchronized with supply line. Commonly, they are used in high power applications for lowering frequencies of such low speed machines, for instance, rolling mills, hoists, excavators and screw propellers [9]. Thyristors closing on natural commutation (that which turns off on zero current) seem to be the only device that meets the voltages and current involved when it comes to high power ratings as in the examples mentioned above. As a means of substitution, IGBT is being used in place of thyristor and it is giving good output.

Cycloconverters can be configured in different number of pulse. The higher the number of pulse, the higher the number of thyristors involved. It can also be said that, the higher number of pulses, the more the harmonic content of the output waveform.

The Simulink software has been used in the design of this cycloconverter. This cycloconverter converts AC to AC, but into a lower frequency AC. IGBT is used in the design of this single phase to single phase cycloconverters as it does not really involve high power ratings. The Simulink model is presented in figure 2.

It consists of 8 thyristors; each of the thyristors has its gate connected to the next. The cathode of one thyristor is connected to the emitter of the other. The connected gates are connected to the control circuit. The parameters of the control circuit are as shown in the figure. The amplitude gives the input and output the peak to peak value of the signal. The period specifies the frequency of the output signal. The input has a known frequency of $50 \mathrm{~Hz}$, and we desire an output frequency of $25 \mathrm{~Hz}$. It should be recalled that the period is the inverse of the frequency, such that the inverse of the output frequency gives us the period used in the simulation.

The cycloconverter is connected as shown in Figure 2 which is operating without circulating current; the nonconducting thyristors should always be kept off otherwise the input power supply could be grounded via the positive and negative thyristor half bridges [1]. When the load current is positive, the output voltage is only controlled by phase control of thyristors T1 to T4 which is termed in this case the positive converter while the other four negative thyristors $\mathrm{T} 5$ to $\mathrm{T} 8$ are kept off and vice versa when the load current is negative. 
Vol. 6, Issue 10, October 2017

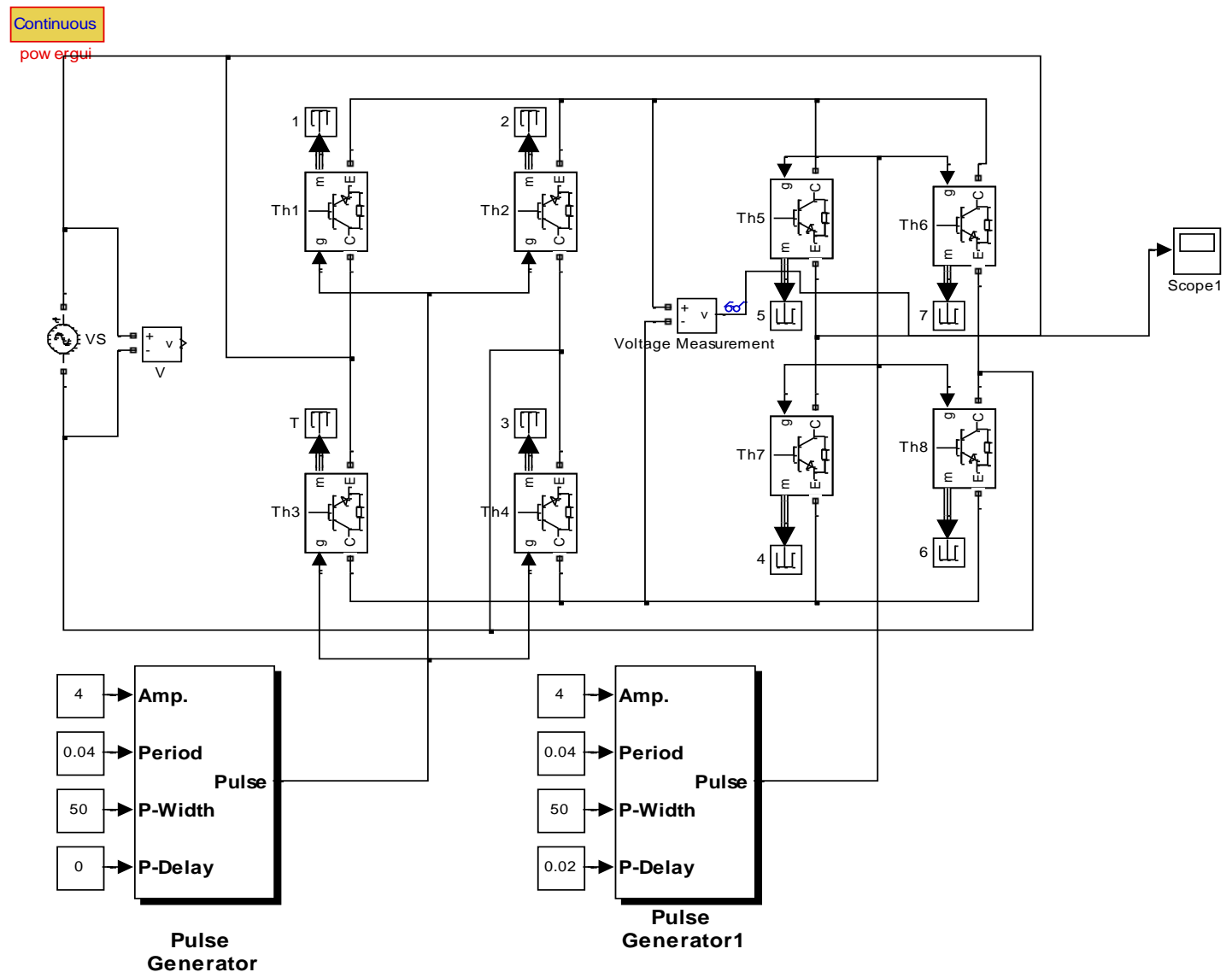

Fig. 2: Simulink Model of a single phase to single phase Cycloconverter

\section{THE CONTROL CIRCUIT OF THE CYLOCONVERTER}

The control circuit of a cycloconverter is what dictates the firing angle of the cycloconverter. The higher the number of pulse and the higher the number of phase being converted, the more complex the design of the control circuit of a cyloconverter.

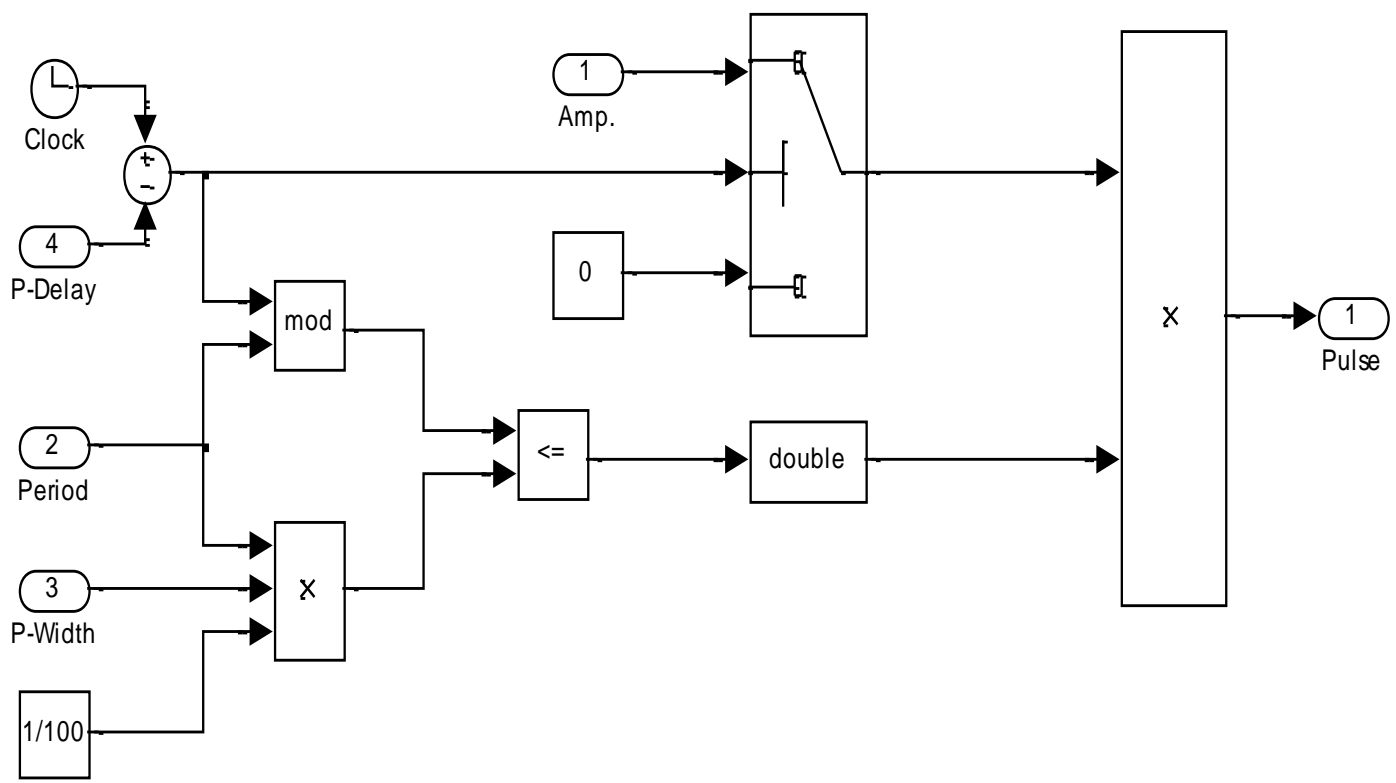

Fig. 3: Control Circuit of Single Phase to Single Phase Cyloconverter 
The control circuit used for this design is analyzed. The control circuit of the single phase to single phase cycloconverter consists of a clock circuit, pulse delay. The pulse delay and the clock are fed into a summer. The output of the summer is fed into the phase delay switch and the modulating block. The period for then firing of the IGBT is determined by the period set which is modulated with the output of the summer. The period and the pulse width are fed into the multiplier. The modulated pulse and the multiplier output are fed into a logic gate to decide, whether to trigger the circuit or not.

\section{THE OUTPUT WAVEFORM of the SINGLE PHASE to SINGLE PHASE CYCLOCONVERTER}

The input and output waveform of the cycloconverter are given below;

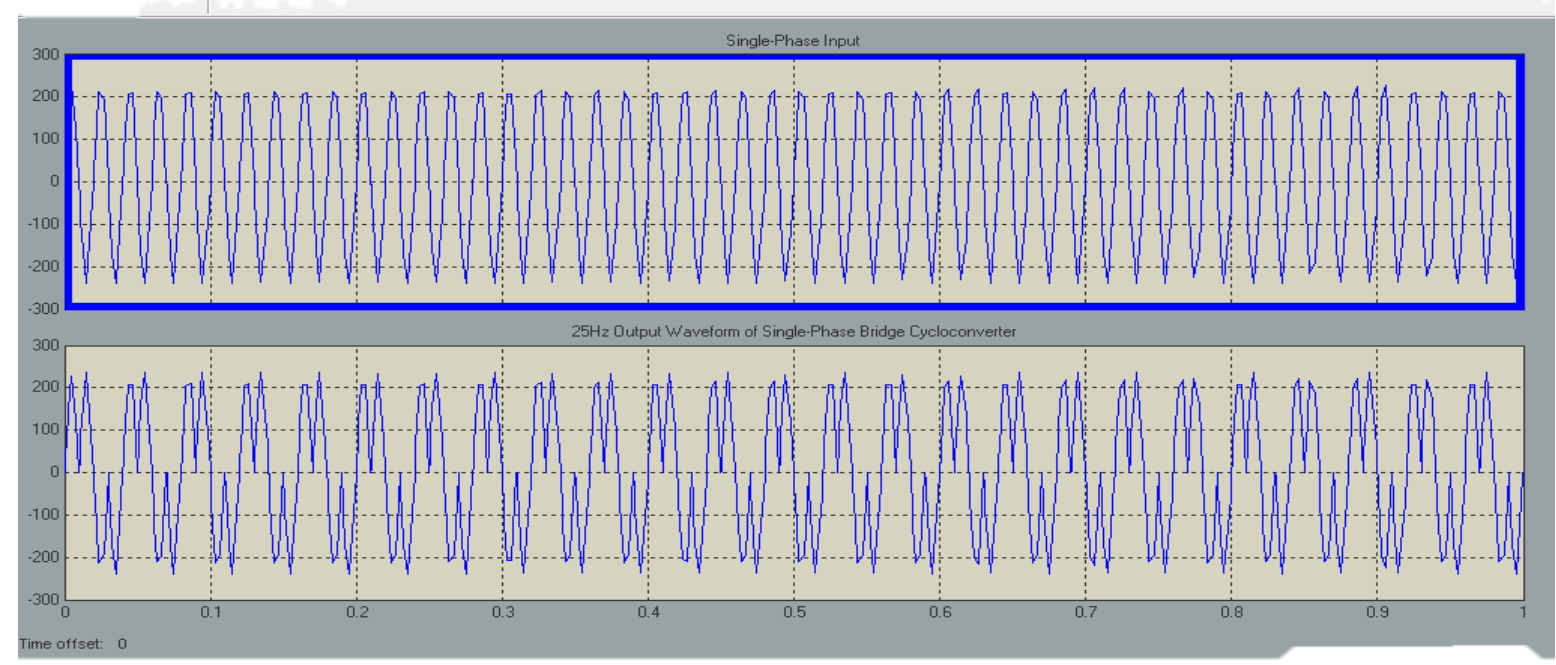

Fig. 4: Input and Output Waveform of Single phase to Single Phase Cyloconverter

From figure 4, it can be observed that in the input waveform, there are four complete oscillations in 0.1 seconds while in the output, the number of complete oscillation made in the same time interval is two. This shows a reduction in the frequency of the output waveform compared to the input. The amplitude of the input and the output remain the same. The cycloconverter designed in this work converts from $50 \mathrm{~Hz}$ frequency to $25 \mathrm{~Hz}$ frequency as observed from the output diagram of figure 5 .

\section{CONCLUSION}

The single phase to single phase cycloconverter has been designed using Matlab Simulink software. The output of the simulation shows that the output frequency is $25 \mathrm{~Hz}$ and the magnitudes of both input and output voltage remain the same. In conclusion, a constant voltage variable frequency cycloconverter has been designed for usage in low frequency demand.

\section{REFERENCES}

1. B. Ozpineci, and L. M. Tolbert, Department of Electrical and Computer Engineering University of Tennessee-Knoxville Knoxville, TN 37996-2100

2. M. H. Rashid, "Power Electronics Circuits, Devices and Application", 6th edition, Copy right 2009, Prentice Hall, Inc Upper Saddle River, NJ.

3. S. Pande and H. Dalvi 'Simulation Of Cycloconverter Based Three Phase Induction Motor', International Journal of Advances Engineering and Technology, Vol. 1,Issue 3,pp.23-33, 2011,

4. M. M. Tayade and S. S Dhamse 'Cycloconverter Drive for AC Motors', International Journal of Electrical Engineering, Vol. 6, No 5 pp 569581, ISSN 0974-2158, 2013

5. K.V.S Bharath and A. Bhardwaj 'Implementing Single Phase Cycloconverter using Single Phase Matrix Converter Topology with Sinusoidal Pulse Width Modulation' International Journal for Technology Research in Engineering, Vol 2, Issue 6 ISSN 2347-4718, pp 532-538, 2015

6. J. Zhang, G.P. Hunter and V.S. Ramsden University of Technology, Sydney, Australia, “A Single phase Input Cycloconverter Driving a Three Phase Motor".

7. Rajib Baran Roy, Md. Ruhul Amin, “Design and Construction of Single Phase Cycloconverter”, International Journal of Recent Technology and Engineering, ISSN: 2277-3878, Volume-1, Issue-3, August 2012

8. S. Kumar, S. Shayana R and V. Kumar P 'Design and Simulation of Control Circuit for Single Phase Cycloconverter' International Journal of Innovative Research in Computer and Communication Engineering, Vol.3, Issue 7, pp.7066-7073, ISSN 2320-9801, 2015

9. B. R. Pelly, Thyristor Phase-Controlled Converters and Cycloconverters, Wiley, New York, 197 